\title{
Article \\ Microcirculatory Function during Endotoxemia-A Functional Citrulline-Arginine-NO Pathway and NOS3 Complex Is Essential to Maintain the Microcirculation
}

\author{
Karolina A. P. Wijnands ${ }^{1, *}$, Dennis M. Meesters ${ }^{1,2}{ }^{\oplus}$, Benjamin Vandendriessche ${ }^{3,4,5,6}$, Jacob J. Briedé ${ }^{7} \mathbb{1}$, \\ Hans M. H. van Eijk ${ }^{1}$, Peter Brouckaert ${ }^{3,4}$, Anje Cauwels ${ }^{3,4,8}$, Wouter H. Lamers ${ }^{9}$ (i) and Martijn Poeze ${ }^{1}$ (D)
}

Citation: Wijnands, K.A.P.; Meesters, D.M.; Vandendriessche, B.; Briedé, J.J.; van Eijk, H.M.H.; Brouckaert, P.; Cauwels, A.; Lamers, W.H.; Poeze, M Microcirculatory Function during

Endotoxemia-A Functional Citrulline-Arginine-NO Pathway and NOS3 Complex Is Essential to Maintain the Microcirculation. Int. J. Mol. Sci. 2021, 22, 11940. https:/ / doi.org/10.3390/ijms222111940

Academic Editor: Tzong-Shyuan Lee

Received: 28 August 2021

Accepted: 1 November 2021

Published: 3 November 2021

Publisher's Note: MDPI stays neutral with regard to jurisdictional claims in published maps and institutional affiliations.

Copyright: (c) 2021 by the authors. Licensee MDPI, Basel, Switzerland. This article is an open access article distributed under the terms and conditions of the Creative Commons Attribution (CC BY) license (https:/ / creativecommons.org/licenses/by/ $4.0 /)$.
1 Department of Surgery, NUTRIM School of Nutrition, Translational Research in Metabolism, Maastricht University Medical Center, 6229 ER Maastricht, The Netherlands; d.meesters@maastrichtuniversity.nl (D.M.M.); hmh.vaneijk@maastrichtuniversity.nl (H.M.H.v.E.); m.poeze@maastrichtuniversity.nl (M.P.)

2 Department of Genetics \& Cell Biology, NUTRIM School of Nutrition, Translational Research in Metabolism, Maastricht University Medical Center, 6229 ER Maastricht, The Netherlands

3 VIB Inflammation Research Center, 9052 Ghent, Belgium; benjamin.vandendriessche@byteflies.com (B.V.); peter.brouckaert@ugent.be (P.B.); acauwels@orionisbio.com (A.C.)

4 Department of Biomedical Molecular Biology, Ghent University, 9000 Ghent, Belgium

5 Byteflies, 2600 Antwerp, Belgium

6 Department of Electrical, Computer and Systems Engineering, Case Western Reserve University, Cleveland, OH 44106, USA

7 Department of Toxicogenomics, GROW School for Oncology and Developmental Biology, Maastricht University Medical Center, 6229 ER Maastricht, The Netherlands; j.briede@maastrichtuniversity.nl Orionis Biosciences, 9052 Ghent, Belgium

9 Department of Anatomy \& Embryology, NUTRIM School of Nutrition, Translational Research in Metabolism, Maastricht University Medical Center, 6229 ER Maastricht, The Netherlands; wh.lamers@maastrichtuniversity.nl

* Correspondence: n.wijnands@maastrichtuniversity.nl; Tel.: +31-650-513-913

Abstract: Competition for the amino acid arginine by endothelial nitric-oxide synthase (NOS3) and (pro-)inflammatory NO-synthase (NOS2) during endotoxemia appears essential in the derangement of the microcirculatory flow. This study investigated the role of NOS2 and NOS3 combined with/without citrulline supplementation on the NO-production and microcirculation during endotoxemia. Wildtype (C57BL6/N background; control; $n=36)$, Nos2-deficient, $(n=40)$, Nos3-deficient $(n=39)$ and Nos2/Nos3-deficient mice $(n=42)$ received a continuous intravenous LPS infusion alone $(200 \mu \mathrm{g}$ total, $18 \mathrm{~h}$ ) or combined with L-citrulline ( $37.5 \mathrm{mg}$, last $6 \mathrm{~h})$. The intestinal microcirculatory flow was measured by side-stream dark field (SDF)-imaging. The jejunal intracellular NO production was quantified by in vivo NO-spin trapping combined with electron spin-resonance (ESR) spectrometry. Amino-acid concentrations were measured by high-performance liquid chromatography (HPLC). LPS infusion decreased plasma arginine concentration in control and $\mathrm{Nos}^{-1-}$ compared to Nos $2^{-/-}$mice. Jejunal NO production and the microcirculation were significantly decreased in control and Nos2 $2^{-1-}$ mice after LPS infusion. No beneficial effects of L-citrulline supplementation on microcirculatory flow were found in $\mathrm{Nos}^{-/-}$or $\mathrm{Nos}^{-/-} / \mathrm{Nos}^{-/-}$mice. This study confirms that L-citrulline supplementation enhances de novo arginine synthesis and NO production in mice during endotoxemia with a functional NOS3-enzyme (control and $\mathrm{Nos}^{-/-}$mice), as this beneficial effect was absent in $\mathrm{Nos}^{-/-}$or Nos2 $2^{-/-} / \mathrm{Nos}^{-/-}$mice.

Keywords: nitric oxide synthase; arginine; microcirculation; endotoxemia; citrulline; NOS3; NOS2

\section{Introduction}

Derangement of the microcirculatory flow is one of the critical pathogenic events in sepsis and appears to be an important directly underling cause for the development of 
multiple organ failure and mortality [1-4]. These alterations in the microcirculation, if not reversed within the first $24 \mathrm{~h}$ after the onset of sepsis (prolonged sepsis), are hypothesized to be the single independent factor in predicting patient outcome [4]. Endothelial damage plays an important role in the development of microcirculatory collapse during prolonged sepsis due to leakage of plasma, and impeded vasodilatation due to a compromised nitric oxide (NO) production [1,2,5-9]. The conversion of arginine to citrulline and NO is the sole source of NO and is mediated by one of the three NO-synthase enzymes (NOS1, NOS2 and NOS3) [10-13]. Several mechanisms are hypothesized to be responsible for the decrease in endothelial NO production during prolonged endotoxin-induced inflammation. The impaired NO production in the microcirculation is thought to be mediated by dysfunction of NOS3 [14], which is mediated at least partly by arginine deficiency $[9,15,16]$. This arginine deficiency, in turn, results from an enhanced utilization of arginine upon the pro-inflammatory upregulation of NOS2 and arginase $[15,17,18]$, and from a decreased import of arginine and/or an impaired resynthesis of arginine from citrulline [15,19-22]. The reduced citrulline bioavailability and production may further deteriorate the already impaired substrate availability in the arginine-NO pathway $[15,19,21,22]$. Furthermore, excessive NOS2-mediated NO production during endotoxemia in non-homogeneously distributed inflammatory cells results in a maldistribution of NO and a "hyperdynamic" microcirculation by shunting [23].

Supplementation of L-citrulline during endotoxemia restored intracellular arginine availability and improved NO production and microcirculatory function [9]. Based on the intracellular co-localization of NOS3 and ASS [24], It is generally hypothesized, but not yet proven that this beneficial effect of L-citrulline is mediated by endothelial NOS3 [25]. We therefore investigated the effect of L-citrulline supplementation in $\mathrm{Nos}^{-/-}, \mathrm{Nos}^{-/-}$, and Nos $2^{-/} / \mathrm{Nos}^{-/-}$mice on intracellular arginine availability, jejunal $\mathrm{NO}$ production and microcirculatory flow in a prolonged endotoxemia model.

\section{Results}

2.1. Plasma Amino Acid Concentrations in Control and Nos-Deficient Mice under Basal and Endotoxemic Conditions

Under basal conditions Nos $2^{-/-}$and $\mathrm{Nos}^{-/-} / \mathrm{Nos}^{-{ }^{-/}}$mice exhibited significantly lower plasma concentrations of arginine than control and $\mathrm{Nos}^{-/-}$mice (Figure 1A). Upon LPS infusion, only the plasma arginine concentrations of control and $\mathrm{Nos}^{-1-}$ mice decreased significantly (Figure 1A). Plasma citrulline concentrations were similar in all mouse lines under both basal and endotoxemic conditions, except for a higher concentration under basal conditions in $\mathrm{Nos}^{-/-}$mice (Figure 1B). Plasma ornithine concentrations were not different between Nos-deficient mice and control mice under basal conditions (Figure 1C). LPS administration increased plasma ornithine concentrations in all mouse lines.

L-citrulline supplementation during endotoxemia resulted in enhanced plasma citrulline concentrations in control, Nos2 $2^{-/-}$and $\mathrm{Nos}^{-/-}$mice (Figure 1B). Remarkably, the effect was $\sim 20$-fold in control, almost twofold less in Nos $2^{-/}$mice, only $\sim$ threefold in Nos3 ${ }^{-/-}$mice, and did not reach significance in Nos2 ${ }^{-/} / \mathrm{Nos}^{-/-}$mice. Citrulline was effectively metabolized to arginine, as its plasma concentration increased $\sim$ fourfold in control + LPS mice and 2-3-fold in Nos2 $2^{-/-}$and $\mathrm{Nos}^{-/-}$mice. Even in Nos2 ${ }^{-/-} / \mathrm{Nos}^{-/-}$LPS-Cit supplemented mice, plasma arginine concentrations increased (Figure 1A). L-citrulline supplementation resulted in increased plasma ornithine concentrations in control, Nos $2^{-/-}$ and $\mathrm{Nos}^{-/-}$mice compared to basal and endotoxemic conditions (Figure 1C).

\subsection{Amino Acid Concentrations in Jejunal Tissue of Control and Nos-Deficient Mice under Basal and Endotoxemic Conditions}

Next, we investigated the amino-acid concentrations in jejunal tissue. Under basal conditions, tissue arginine concentrations were similar in Nos $2^{-/-}$and $\mathrm{Nos}^{-/-} / \mathrm{Nos}^{-/-}$ mice, but were $\sim$ twofold higher in $\mathrm{Nos}^{-/-}$mice (Figure 2A). LPS infusion decreased jejunal arginine concentrations in control and $\mathrm{Nos}^{-/-}$mice only $(p<0.01$ and $p<0.05$, respectively, $n=7$; Figure $2 \mathrm{~A}$ ). Under basal conditions, jejunal citrulline concentrations were 
significantly higher in $\mathrm{Nos}^{-/-}$mice than in the other mouse lines (Figure 2B). Endotoxemia decreased jejunal citrulline concentration in control and $\mathrm{Nos}^{-/-}$mice, whereas it increased jejunal citrulline concentration slightly, but significantly, in Nos $2^{-/-}$mice (Figure $2 \mathrm{~B}$ ). Jejunal ornithine concentration was $\sim 1.5$-fold higher in $\mathrm{Nos}^{-/-}$mice than in control and Nos $2^{-/-}$Nos $^{-/-}$mice $(p<0.05, n=7$; Figure 2 C). LPS administration increased the intracellular ornithine concentrations in control and $\mathrm{Nos}^{-/-} / \mathrm{Nos}^{-/-}$mice (Figure $2 \mathrm{C}$ ).

A

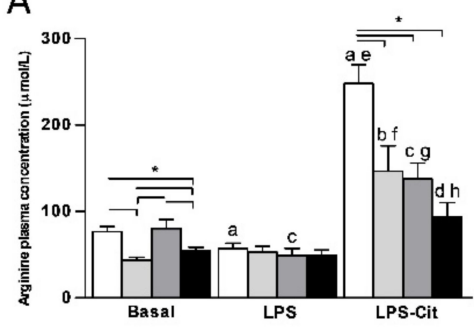

B

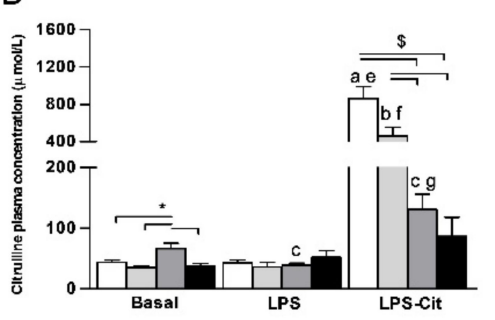

C

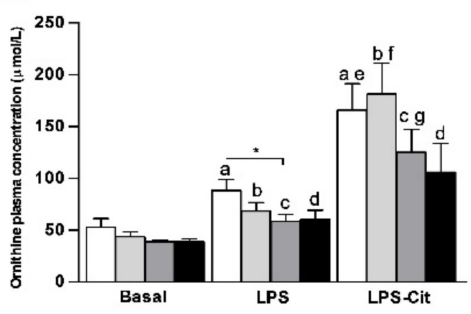

$\square$ Control $\square$ Nos2 $\square$ Nos3 $\square$ Nos2 $\% / \mathrm{Nos}^{\%}$

Figure 1. Plasma arginine, citrulline and ornithine concentrations in control and Nos-deficient mice under basal and endotoxemic conditions with or without L-citrulline supplementation. (A) Plasma arginine concentrations in control and Nos-deficient mice under basal and endotoxemic conditions with or without L-citrulline supplementation. (B) Plasma citrulline concentrations in control and Nos-deficient mice under basal and endotoxemic conditions with or without L-citrulline supplementation. (C) Plasma ornithine concentrations in control and Nos-deficient mice under basal and endotoxemic conditions with or without L-citrulline supplementation. ${ }^{*} p$-value $<0.05$; $\$ p$-value $<0.001$; a $p$-value $<0.05$ vs. control mice under basal conditions; b $p$-value $<0.05$ vs. Nos $2^{-/-}$mice under basal conditions; c $p$-value $<0.05$ vs. $N_{o s} 3^{-/-}$mice under basal conditions; d $p$-value $<0.05$ vs. Nos $2^{-/-} / N_{o s} 3^{-/-}$mice under basal conditions; e $p$-value $<0.05$

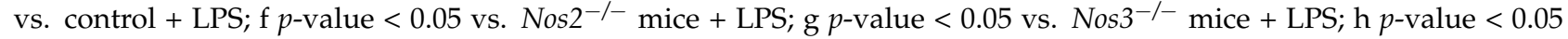
vs. Nos $2^{-/-} /$Nos3 $^{-/-}$mice + LPS. Data are shown as mean \pm SEM. Statistical significance was determined with one-way ANOVA and post-hoc Bonferroni correction between groups.

A

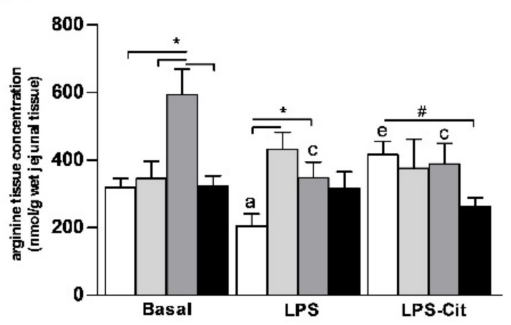

B

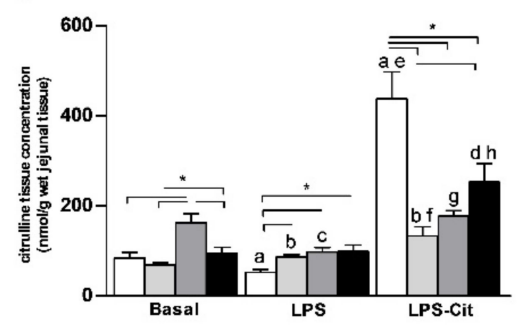

C

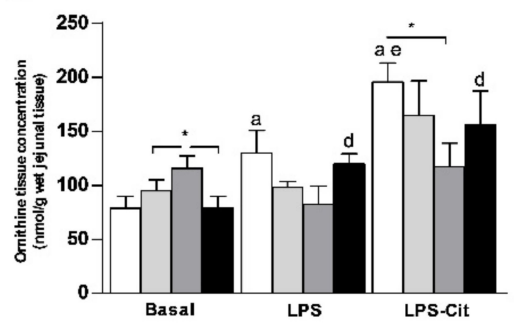

Figure 2. Jejunal arginine, citrulline and ornithine concentrations in control and Nos-deficient mice under basal and endotoxemic conditions with or without L-citrulline supplementation. (A) Jejunal arginine concentrations in control and Nos-deficient mice under basal and endotoxemic conditions with or without L-citrulline supplementation. (B) Jejunal citrulline concentrations in control and Nos-deficient mice under basal and endotoxemic conditions with or without L-citrulline supplementation. (C) Jejunal ornithine concentrations in control and Nos-deficient mice under basal and endotoxemic conditions with or without L-citrulline supplementation. ${ }^{*} p$-value $<0.05$; ${ }^{\#} p$-value $<0.01$; a $p$-value $<0.05$ vs. control mice under basal conditions; b $p$-value $<0.05$ vs. Nos $2^{-/-}$mice under basal conditions; c $p$-value $<0.05$ vs. $\mathrm{Nos}^{-/-}$mice under basal conditions; d $p$-value $<0.05$ vs. Nos $2^{-/-} / \mathrm{Nos}^{-/-}$mice under basal conditions; e $p$-value $<0.05$ vs. control + LPS; f $p$-value $<0.05$ vs. Nos $2^{-/-}$mice + LPS; g $p$-value $<0.05$ vs. Nos ${ }^{-/-}$mice + LPS; h $p$-value $<0.05$ vs. Nos $2^{-/-} / \mathrm{Nos}^{-/-}$mice + LPS. Data are shown as mean \pm SEM. Statistical significance was determined with one-way ANOVA and post-hoc Bonferroni correction between groups. 
Citrulline supplementation during endotoxemia resulted in a significant increase in citrulline concentrations in jejunal tissue off all mouse lines (Figure 2B). The increase was $\sim 9$-fold for control mice and only $\sim 2$-fold for the Nos-deficient lines. Reflecting this difference, citrulline supplementation during endotoxemia only enhanced jejunal arginine concentrations in control mice ( $p<0.01, n=7$, Figure 2A). Under the same conditions, jejunal ornithine concentrations were increased in control and Nos-deficient mice, but did not reach significance in $\mathrm{Nos}^{-/-} / \mathrm{Nos}^{-/-}$mice (Figure $2 \mathrm{C}$ ).

\subsection{L-Citrulline Enhances the Intestinal NO Production in Control and Nos2-Deficient Mice}

Under basal conditions, intestinal intracellular NO concentrations were lower in Nosdeficient than in control mice, but reached significance in $\mathrm{Nos}^{-/-} / \mathrm{Nos}^{-/-}$mice only (Figure 3). The intestinal NO production in Nos2 $2^{-/-} / \mathrm{Nos}^{-/-}$mice was $\sim$ twofold lower than that in control mice $(p<0.05$; Figure 3$)$.

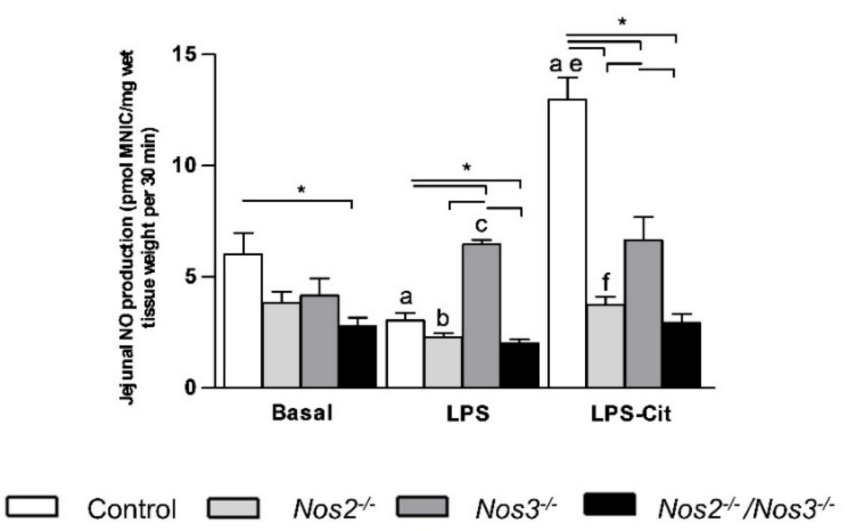

Figure 3. NO production in jejunal tissue of control and Nos-deficient mice during basal and endotoxemic conditions, and after L-citrulline supplementation during endotoxemia. Basal jejunal NO production (in pmol MNIC/mg wet jejunal tissue) in control and Nos-deficient mice under basal and endotoxemic conditions with or without L-citrulline supplementation. ${ }^{*} p$-value $<0.05$; a $p$-value $<0.05$ vs. control mice under basal conditions; $\mathrm{b} p$-value $<0.05$ vs. Nos $2^{-/-}$mice under basal conditions; $\mathrm{c} p$-value $<0.05$ vs. Nos3 ${ }^{-/}$mice under basal conditions; e $p$-value $<0.05$ vs. control + LPS; f $p$-value $<0.05$ vs. Nos $2^{-/-}$mice + LPS. Data are shown as mean $\pm \mathrm{SEM}$. Statistical significance was determined with one-way ANOVA and post-hoc Bonferroni correction between groups.

LPS infusion resulted in a significant decrease in the jejunal $\mathrm{NO}$ production of control and Nos $2^{-1-}$ mice (Figure 3, $n=5$ ), whereas it increased jejunal NO production $\sim 1.5$ fold in $\mathrm{Nos}^{-/-}$mice $(p<0.05, n=5$; Figure 3). Interestingly, the NO production in Nos $2^{-/-}$Nos $^{-/-}$mice was not altered and remained significantly lower than in control mice. L-citrulline supplementation during endotoxemia enhanced jejunal NO production in control and Nos2 ${ }^{-/}$mice (Figure 3, $n=5$, both $p<0.05$ ) and was $\sim 3$-fold higher in control than in Nos $2^{-/-}$mice. The increased NO production due to endotoxemia in Nos $3^{-1-}$ mice was not further increased by L-citrulline supplementation ( $p=0.9$; Figure 3$)$.

\subsection{Detrimental Effects of Nos3 Deficiency on Microcirculatory Flow during Endotoxemia}

Under basal conditions the total number of perfused vessels and the number of perfused vessels per villus were lower in the $\mathrm{Nos}^{-/-}$and Nos $2^{-/-} / \mathrm{Nos}^{-/-}$mice than in control or Nos $2^{-1-}$ mice (Figure 4A,B). Endotoxemia reduced the total number of perfused vessels and the number of perfused vessels per villus in control and Nos2 ${ }^{-1-}$ mice, but did not alter these parameters in $\mathrm{Nos}^{-/-}$or Nos $2^{-/-} / \mathrm{Nos}^{-/-}$mice (Figure $4 \mathrm{~A}, \mathrm{~B}$ ). Under endotoxemic conditions, the total number of perfused vessels and vessels per villus were similar in all mouse lines. L-Citrulline supplementation during endotoxemia increased both parameters in control and Nos $2^{-/-}$mice (Figure $4 \mathrm{~A}, \mathrm{~B}, p<0.05$ for both), but not in $\mathrm{Nos}^{-/-}$or Nos2 ${ }^{-/-} / \mathrm{Nos}^{-/-}$mice (Figure $4 \mathrm{~A}, \mathrm{~B}$ ). 
A

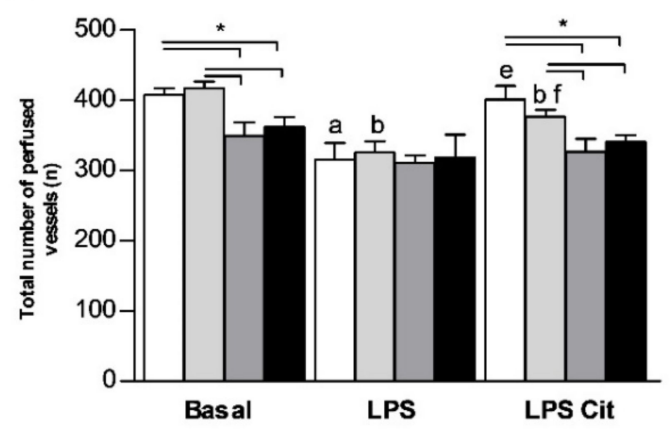

B

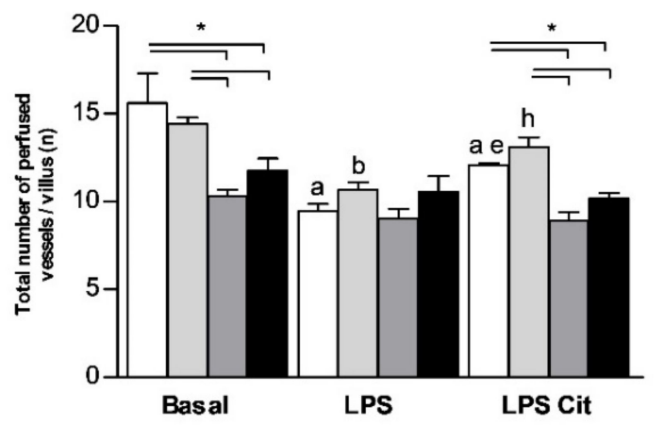

Control $\square$ Nos2 $^{-} \square$ Nos3 $^{-} \square$ Nos2 $^{-1} / \mathrm{Nos}^{-}$

Figure 4. Microcirculatory flow measurements with SDF-imaging in the jejunal villi. (A) The total number of perfused vessels in control and Nos-deficient mice under basal and endotoxemic conditions with or without L-citrulline supplementation. (B) The number of perfused vessels per villus in control and Nos-deficient mice under basal and endotoxemic conditions with or without L-citrulline supplementation. * $p$-value $<0.05$; a $p$-value $<0.05$ vs. control mice during basal conditions; $\mathrm{b}$ $p$-value $<0.05$ vs. Nos $2^{-/-}$mice during basal conditions; e $p$-value $<0.05$ vs. control + LPS; $f$-value $<0.05$ vs. Nos $2^{-/-}$ mice + LPS; h $p$-value $<0.05$ vs. Nos $2^{-/} /$Nos3 $^{-/-}$mice + LPS. Data are shown as mean \pm SEM. Statistical significance was determined with one-way ANOVA and post-hoc Bonferroni correction between groups.

\section{Discussion}

The results presented in this study demonstrate that Nos3 deficiency does not decrease jejunal tissue NO production, but does result in an impaired microcirculation as judged from the decreased number of perfused vessels under basal and endotoxemic conditions. Our findings further reveal that, in the absence of Nos3, endotoxemia and supplementation of L-citrulline does not affect the microcirculation, demonstrating that the positive effects of L-citrulline supplementation depend on the presence of a functional NOS3 enzyme. The effects of endotoxemia and L-citrulline supplementation were similar in control and Nos $2^{-/-}$mice, which shows that NOS2 does not contribute to the vasodilatory effect of NO in jejunal villi.

The microcirculation is a complex system, in which endothelial NO production plays a key role in regulating blood flow $[1,2,4,5,26]$. The role of NOS3 in endothelial NO production and microcirculatory homeostasis is well established under physiological conditions, but it has remained unclear thus far whether NOS3-dependent NO production is the exclusive source of NO-dependent microcirculatory flow. Endotoxemic conditions increase Nos2 expression and decrease that of Nos3 [27], which is accompanied by the development of an impaired or shunted microvascular perfusion $[2,4,5,23,27,28]$. Historically, deletion or inhibition of NOS2 was hypothesized to be the key to prevent or treat the detrimental effects of endotoxemia on microvascular perfusion [23,29-31]. Normally, endotoxemia results in an increased expression of Nos 2 mRNA and protein, which leads to an increased NO-production [32], but this overexpression of Nos2 does not enhance hypotension [32,33]. However, due to non-homogeneous expression of Nos2 in tissues, shunting of the microvascular flow during endotoxemia occurs [23]. A better microvascular responsiveness and a lower mortality during experimental sepsis induced by cecal ligation and puncture were reported in Nos2-deficient animals compared to control animals [34]. Our findings are at variance with these data, as the Nos2-deficient mice in our study demonstrated an impaired NO-production and a decreased number of perfused vessels during prolonged endotoxemia, similar to control mice. These results indicate that NOS2 does not play a significant role in the intestinal $\mathrm{NO}$-production and the regulation of the microcirculation during prolonged endotoxemia. Furthermore, downregulation of Nos3 expression during endotoxemia [9] may further contribute to the impaired NO production during endotox- 
emia in these Nos2-deficient animals. In addition, administration of LPS, which induced an increased NOS2-derived NO-production, did not result in an altered microcirculation in Nos3-deficient mice. Therefore, our data imply a key function for NOS3 in the maintenance of the intestinal microcirculation under basal and endotoxemic conditions.

The influence of NO on the vascular tone has led to several experimental studies investigating the influence of genetic ablation of Nos genes $[8,31,35]$. In the absence of NOS3, a $50 \%$ decrease in basal NO concentrations was observed in brain tissue of Nos3-deficient compared to wild-type mice [36]. Despite the lower NO-production in the absence of NOS3, angiogenesis was normal [35]. Compensation by NOS1 was shown to be responsible for the maintenance of an adequate NO production [36-40]. In this respect it is of interest that the observed lower basal NO production in the current study in Nos3 ${ }^{-/-}$and Nos2 ${ }^{-/-} / \mathrm{Nos}^{-/-}$ compared to control mice was accompanied by a decrease in the number of perfused vessels, which indicates that intestinal NOS1 does not compensate for the absence of NOS3, and that NOS3 is essential to maintain the intestinal perfusion. In order to receive a sufficient amount of NOS3-derived NO production, a continuous intracellular arginine availability is key.

This intracellular availability of arginine depends on arginine regeneration from Lcitrulline or protein degradation. Regeneration of intracellular arginine from citrulline via argininosuccinate synthetase is essential to maintain NOS3-dependent NO production in endothelial cells [25,41]. As many as three independent intracellular arginine pools have been postulated [24], but more recent literature suggests that, at least in case of enhanced arginine consumption by arginase in endothelial cells, the subcellular location of arginine is less important in maintaining NOS3-derived NO production [42]. We previously observed enhanced arginase activity during endotoxemia [9,43], as determined from the increased ornithine plasma and tissue concentrations in control mice. Furthermore, we showed that, in the absence of arginase- 1 in endothelial cells or macrophages, only NOS2-derived NO production significantly increased during endotoxemia, whereas NOS3-derived NO production did not benefit from the arginase-1 deficiency [43]. This discrepancy between our results and those of Elms et al. [42] may result from the enhanced NOS2 activity in arginase- 1 deficient animals.

We previously demonstrated that L-citrulline supplementation during endotoxemia resulted in enhanced arginine concentrations both in plasma and tissue [9], while arginine supplementation in this model did not increase tissue arginine concentration. In addition, in Nos $2^{-/-}$mice, L-citrulline supplementation exhibited similar effects as in control mice: increased plasma arginine concentrations, an increased intracellular NO production and an enhanced microcirculatory flow. These results suggest that the beneficial effects of L-citrulline supplementation on NO production and microcirculatory flow are mediated by NOS3. The lack of effects of citrulline supplementation in the Nos2 ${ }^{-/-} / \mathrm{Nos}^{-/-}$double knockout mice further implies that NOS1 is not able to compensate for the lack of NOS3. Therefore, our results further underline the subcellular localization of citrulline and NOS3 to maintain a NOS3-specific arginine pool as a substrate for NOS3-derived NO-production in the microcirculation.

To determine the possible potential clinical administration of citrulline and further in vivo implications, we previously conducted a randomized double-blinded control, placebo-controlled crossover study in healthy athletes in which oral citrulline was administrated prior to $1 \mathrm{~h}$ of strenuous exercise at $70 \%$ of the individual pre-assessed maximal workload capacity. The enhanced arginine availability in the L-citrulline supplemented group resulted in a preserved splanchnic perfusion and reduced intestinal injury during exercise [44]. In line with this previous study, the current study results suggest that L-citrulline is a potential clinical application for patients during endotoxemic or septic conditions accompanied by an impaired microcirculation and arginine deficient state. In conclusion, our study demonstrates that L-citrulline supplementation results in an enhanced de novo arginine synthesis and NO production in control and Nos2 $2^{-/-}$mice during 
endotoxemia. However, these beneficial effects of L-citrulline supplementation on the microcirculation depend entirely on a functional Nos3 gene.

\section{Materials and Methods}

\subsection{Animals}

To investigate the role of NOS2 and NOS3 on the microcirculatory flow and the NO production during endotoxemia, male C57Bl6 (control; $n=36)$, Nos2 $2^{-/}$[45] $(n=40)$, Nos3 $^{-/-}$[39] $(n=39)$ and Nos $2^{-/} /$Nos3 $^{-/-}$mice $(n=42)$ were obtained from the Department for Molecular Biomedical Research, University Ghent, Belgium. The Nos2 ${ }^{-1}$ [45] and $\mathrm{Nos}^{-/-}$mice [39] were initially obtained from Jackson laboratories. Nos $2^{-/-} / \mathrm{Nos}^{-/-}$ double knockout mice were produced at the Department of Biomedical Molecular Biology. All mice were transported to the Centralized Animal Facilities at Maastricht University and allowed a three weeks adaptation period. The mice were two to three months old, weighed 23-28 g and were individually housed at room temperature on a $12 \mathrm{~h}$ light-dark cycle, fed standard lab chow (Hope Farms, Woerden, The Netherlands) and water ad libitum until the experimental phase of the study. The protocol was approved by the Committee on the Ethics of Animal Experiments of the Maastricht University Medical Center (Permit Number: 2010-172).

\subsection{Experimental Design}

The experimental protocol and surgical procedures were described in detail elsewhere [9]. In brief, a jugular vein catheter was implanted 4 days prior to the experimental phase of the study. At day four, mice were randomly allocated to receive lipopolysaccharide (LPS; E. coli O55:B5, Sigma Aldrich, St. Louis, MO, USA, $0.4 \mu \mathrm{g} \times \mathrm{g}_{\text {bodyweight }}{ }^{-1} \times \mathrm{h}^{-1}$; $n=109)$ or sterile $0.9 \%$ saline $(n=48)$. In total 13 mice died during the endotoxemia infusion (4 Nos2 $2^{-/-}, 3 \mathrm{Nos}^{-/-}$and $6 \mathrm{Nos}^{-/-} / \mathrm{Nos}^{-/-}$mice). During the final $6 \mathrm{~h}$ L-citrulline $(6.25 \mathrm{mg} / \mathrm{h} ; n=48$; "LPS-Cit" group) or the placebo amino acid L-alanine $(12.5 \mathrm{mg} / \mathrm{h}$; $n=48$; "LPS" group) was administered simultaneously with the LPS infusate. The control group was treated with $0.9 \%$ saline and L-alanine ( $n=48$; "control" group). In total, mice received $1.5 \mathrm{~mL}$ fluid during the $18 \mathrm{~h}$ infusion protocol $(83 \mu \mathrm{L} / \mathrm{h})$. At the end of the $18 \mathrm{~h}$ infusion period, mice were anesthetized as described [9]. In vivo tissue NO production $(n=60)$ and jejunal microcirculation $(n=84)$ were measured as described in brief below. Arterial blood was sampled via a cardiac puncture. Organs were then harvested, snap frozen in liquid nitrogen and stored in $-80^{\circ} \mathrm{C}$ until further analysis.

\subsection{Plasma and Tissue Amino-Acid Concentration Measurements}

After deproteinization, plasma and jejunal amino-acid concentrations were determined by high-performance liquid chromatography (HPLC) [9].

\subsection{In Vivo Tissue NO Production}

The in vivo NO production in jejunal tissue was determined in mice $(n=60)$ injected with spin trap agents and quantified as mono-nitrosyl iron complexes (MNIC) with $\mathrm{Fe}^{2+}$ dithiocarbamate complexes with electron spin resonance (ESR) spectroscopy [9]. NO concentrations were calculated from the height of the three-line NO amplitude using Bruker WINEPR software as previously described in more detail [9].

\subsection{Jejunal Microcirculation Measurements with SDF Imaging}

The mucosal microcirculation in the jejunal villi was microscopically visualized with the side-stream dark-field (SDF) imager (Microscan, Amsterdam, the Netherlands) [46,47], as described [9]. In brief, circulation, quantified as the total number of perfused vessels per view and the total number of perfused vessels per villus, was determined using Automated Vascular Analysis software 3.0 (Microscan, Amsterdam, the Netherlands), adjusted according to de Backer et al. $[28,48,49]$. The average microvascular flow index (MFI), a parameter for the predominant type of flow in the villi in the four quadrants of 
an image, was scored semiquantitatively $(0=$ absent, $1=$ intermittent, with at least $50 \%$ of the time no flow, $2=$ sludging, $3=$ normal or $4=$ hyperdynamic flow) [28]. All imaging experiments were done by an experienced investigator and images were analyzed by two independent blinded experienced researchers.

\subsection{Statistical Analysis}

Statistical analysis of the data was performed using GraphPad Prism 6 (GraphPad, San Diego, CA, USA). One-way analysis of variance (ANOVA) was performed with posthoc Bonferroni correction between groups to determine significant differences. Data are represented as mean and standard error of the mean (SEM). $p$-values smaller than 0.05 were considered as statistically significant.

Author Contributions: The authors' responsibilities were as follows; K.A.P.W. and M.P. designed research; K.A.P.W. and D.M.M. conducted the research and collected the data; A.C., P.B. and B.V. bred the mice; K.A.P.W., D.M.M., J.J.B., B.V., P.B. and A.C. analyzed the data; H.M.H.v.E. determined the amino-acid concentrations; K.A.P.W. and M.P. drafted the manuscript; K.A.P.W., W.H.L. and M.P. had primary responsibility for final content. All authors have read and agreed to the published version of the manuscript.

Funding: This research was funded by grants from ZonMw Innovational Research Incentives (VENI 916.76.191) and the European Society of Intensive Care Medicine Eli Lilly Sepsis Elite Award 2008.

Institutional Review Board Statement: The study was conducted according to the guidelines of the Declaration of Helsinki, and approved by the Ethics Committee of Animal Experiments of the Maastrichst University Medical Center (Permit Number: 2010-172).

Informed Consent Statement: Not applicable.

Acknowledgments: The authors wish to thank Kyowa Hakko for providing the L-citrulline.

Conflicts of Interest: The authors declare no conflict of interest. The funders had no role in the design of the study; in the collection, analyses, or interpretation of data; in the writing of the manuscript, or in the decision to publish the results.

\section{References}

1. Trzeciak, S.; Cinel, I.; Phillip Dellinger, R.; Shapiro, N.I.; Arnold, R.C.; Parrillo, J.E.; Hollenberg, S.M. Resuscitating the microcirculation in sepsis: The central role of nitric oxide, emerging concepts for novel therapies, and challenges for clinical trials. Acad. Emerg. Med. 2008, 15, 399-413. [CrossRef] [PubMed]

2. Pool, R.; Gomez, H.; Kellum, J.A. Mechanisms of Organ Dysfunction in Sepsis. Crit. Care Clin. 2018, 34, 63-80. [CrossRef] [PubMed]

3. Sakr, Y.; Dubois, M.-J.; De Backer, D.; Creteur, J.; Vincent, J.-L. Persistent microcirculatory alterations are associated with organ failure and death in patients with septic shock. Crit. Care Med. 2004, 32, 1825-1831. [CrossRef] [PubMed]

4. Lipinska-Gediga, M. Sepsis and septic shock-is a microcirculation a main player? Anaesthesiol. Intensive Ther. 2016, 48, 261-265. [CrossRef] [PubMed]

5. Joffre, J.; Hellman, J.; Ince, C.; Ait-Oufella, H. Endothelial Responses in Sepsis. Am. J. Respir. Crit. Care Med. 2020, 202, 361-370. [CrossRef] [PubMed]

6. Cobb, J.P.; Buchman, T.G.; Karl, I.E.; Hotchkiss, R.S. Molecular biology of multiple organ dysfunction syndrome: Injury, adaptation, and apoptosis. Surg. Infect. 2000, 1, 207-213, discussion 214-205. [CrossRef] [PubMed]

7. Trzeciak, S.; Dellinger, R.P.; Parrillo, J.E.; Guglielmi, M.; Bajaj, J.; Abate, N.L.; Arnold, R.C.; Colilla, S.; Zanotti, S.; Hollenberg, S.M. Early microcirculatory perfusion derangements in patients with severe sepsis and septic shock: Relationship to hemodynamics, oxygen transport, and survival. Ann. Emerg. Med. 2007, 49, 88-98.e2. [CrossRef]

8. Kavdia, M.; Popel, A.S. Contribution of nNOS- and eNOS-derived NO to microvascular smooth muscle NO exposure. J. Appl. Physiol. 2004, 97, 293-301. [CrossRef]

9. Wijnands, K.A.; Vink, H.; Briede, J.J.; van Faassen, E.E.; Lamers, W.H.; Buurman, W.A.; Poeze, M. Citrulline a more suitable substrate than arginine to restore NO production and the microcirculation during endotoxemia. PLoS ONE 2012, 7, e37439. [CrossRef]

10. Bruins, M.J.; Lamers, W.H.; Meijer, A.J.; Soeters, P.B.; Deutz, N.E. In vivo measurement of nitric oxide production in porcine gut, liver and muscle during hyperdynamic endotoxaemia. Br. J. Pharmacol. 2002, 137, 1225-1236. [CrossRef]

11. Flam, B.R.; Eichler, D.C.; Solomonson, L.P. Endothelial nitric oxide production is tightly coupled to the citrulline-NO cycle. Nitric Oxide 2007, 17, 115-121. [CrossRef] 
12. Kelm, M. Nitric oxide metabolism and breakdown. Biochim. Biophys. Acta 1999, 1411, 273-289. [CrossRef]

13. Luiking, Y.C.; Engelen, M.P.; Deutz, N.E. Regulation of nitric oxide production in health and disease. Curr. Opin. Clin. Nutr. Metab. Care 2010, 13, 97-104. [CrossRef]

14. Chen, C.-A.; Wang, T.-Y.; Varadharaj, S.; Reyes, L.A.; Hemann, C.; Talukder, M.A.H.; Chen, Y.-R.; Druhan, L.J.; Zweier, J.L. S-glutathionylation uncouples eNOS and regulates its cellular and vascular function. Nature 2010, 468, 1115-1118. [CrossRef]

15. Luiking, Y.C.; Poeze, M.; Ramsay, G.; Deutz, N.E. Reduced citrulline production in sepsis is related to diminished de novo arginine and nitric oxide production. Am. J. Clin. Nutr. 2009, 89, 142-152. [CrossRef]

16. Freund, H.; Atamian, S.; Holroyde, J.; Fischer, J.E. Plasma amino acids as predictors of the severity and outcome of sepsis. Ann. Surg. 1979, 190, 571-576. [CrossRef]

17. Durante, W.; Johnson, F.K.; Johnson, R.A. Arginase: A critical regulator of nitric oxide synthesis and vascular function. Clin. Exp. Pharmacol. Physiol. 2007, 34, 906-911. [CrossRef]

18. Ochoa, J.B.; Udekwu, A.O.; Billiar, T.R.; Curran, R.D.; Cerra, F.B.; Simmons, R.L.; Peitzman, A.B. Nitrogen oxide levels in patients after trauma and during sepsis. Ann. Surg. 1991, 214, 621-626. [CrossRef]

19. Kao, C.C.; Bandi, V.; Guntupalli, K.K.; Wu, M.; Castillo, L.; Jahoor, F. Arginine, citrulline and nitric oxide metabolism in sepsis. Clin. Sci. 2009, 117, 23-30. [CrossRef]

20. Argaman, Z.; Young, V.R.; Noviski, N.; Castillo-Rosas, L.; Lu, X.M.; Zurakowski, D.; Cooper, M.; Davison, C.; Tharakan, J.F.; Ajami, A.; et al. Arginine and nitric oxide metabolism in critically ill septic pediatric patients. Crit. Care Med. 2003, 31, 591-597. [CrossRef]

21. Crenn, P.; Neveux, N.; Chevret, S.; Jaffray, P.; Cynober, L.; Melchior, J.C.; Annane, D.; COIITSS Study Group. Plasma 1-citrulline concentrations and its relationship with inflammation at the onset of septic shock: A pilot study. J. Crit. Care 2013, 29, 315.e1-315.e6. [CrossRef]

22. Elwafi, F.; Curis, E.; Zerrouk, N.; Neveux, N.; Chaumeil, J.C.; Arnaud, P.; Cynober, L.; Moinard, C. Endotoxemia affects citrulline, arginine and glutamine bioavailability. Eur. J. Clin. Investig. 2012, 42, 282-289. [CrossRef]

23. Elbers, P.W.G.; Ince, C. Bench-to-bedside review: Mechanisms of critical illness-Classifying microcirculatory flow abnormalities in distributive shock. Crit. Care 2006, 10, 221. [CrossRef]

24. Shen, L.J.; Beloussow, K.; Shen, W.C. Accessibility of endothelial and inducible nitric oxide synthase to the intracellular citrullinearginine regeneration pathway. Biochem. Pharmacol. 2005, 69, 97-104. [CrossRef]

25. Bahadoran, Z.; Mirmiran, P.; Kashfi, K.; Ghasemi, A. Endogenous flux of nitric oxide: Citrulline is preferred to Arginine. Acta Physiol. 2021, 231, e13572. [CrossRef]

26. Ince, C.; Sinaasappel, M. Microcirculatory oxygenation and shunting in sepsis and shock. Crit. Care Med. 1999, 27, 1369-1377. [CrossRef]

27. Chen, K.; Inoue, M.; Wasa, M.; Fukuzawa, M.; Kamata, S.; Okada, A. Expression of endothelial constitutive nitric oxide synthase mRNA in gastrointestinal mucosa and its downregulation by endotoxin. Life Sci. 1997, 61, 1323-1329. [CrossRef]

28. Boerma, E.C.; Mathura, K.R.; van der Voort, P.H.; Spronk, P.E.; Ince, C. Quantifying bedside-derived imaging of microcirculatory abnormalities in septic patients: A prospective validation study. Crit. Care 2005, 9, R601-R606. [CrossRef]

29. Hollenberg, S.M.; Broussard, M.; Osman, J.; Parrillo, J.E. Increased microvascular reactivity and improved mortality in septic mice lacking inducible nitric oxide synthase. Circ. Res. 2000, 86, 774-778. [CrossRef]

30. Kubes, P.; McCafferty, D.M. Nitric oxide and intestinal inflammation. Am. J. Med. 2000, 109, 150-158. [CrossRef]

31. Cobb, J.P.; Hotchkiss, R.S.; Swanson, P.E.; Chang, K.; Qiu, Y.; Laubach, V.E.; Karl, I.E.; Buchman, T.G. Inducible nitric oxide synthase (iNOS) gene deficiency increases the mortality of sepsis in mice. Surgery 1999, 126, 438-442. [CrossRef]

32. Bultinck, J.; Sips, P.; Vakaet, L.; Brouckaert, P.; Cauwels, A. Systemic NO production during (septic) shock depends on parenchymal and not on hematopoietic cells: In vivo iNOS expression pattern in (septic) shock. Faseb. J. 2006, 20, 2363-2365. [CrossRef] [PubMed]

33. Cauwels, A.; Bultinck, J.; De Zwaef, R.; Vandendriessche, B.; Magez, S.; Brouckaert, P. Nitric oxide production by endotoxin preparations in TLR4-deficient mice. Nitric Oxide 2014, 36, 36-43. [CrossRef] [PubMed]

34. Okamoto, I.; Abe, M.; Shibata, K.; Shimizu, N.; Sakata, N.; Katsuragi, T.; Tanaka, K. Evaluating the role of inducible nitric oxide synthase using a novel and selective inducible nitric oxide synthase inhibitor in septic lung injury produced by cecal ligation and puncture. Am. J. Respir. Crit. Care Med. 2000, 162, 716-722. [CrossRef]

35. Al-Shabrawey, M.; El-Remessy, A.; Gu, X.; Brooks, S.S.; Hamed, M.S.; Huang, P.; Caldwell, R.B. Normal vascular development in mice deficient in endothelial NO synthase: Possible role of neuronal NO synthase. Mol. Vis. 2003, 9, 549-558.

36. Wei, X.Q.; Charles, I.G.; Smith, A.; Ure, J.; Feng, G.J.; Huang, F.P.; Xu, D.; Muller, W.; Moncada, S.; Liew, F.Y. Altered immune responses in mice lacking inducible nitric oxide synthase. Nature 1995, 375, 408-411. [CrossRef]

37. Massberg, S.; Eisenmenger, S.; Enders, G.; Krombach, F.; Messmer, K. Quantitative analysis of small intestinal microcirculation in the mouse. Res. Exp. Med. 1998, 198, 23-35. [CrossRef]

38. Burnett, A.L.; Nelson, R.J.; Calvin, D.C.; Liu, J.X.; Demas, G.E.; Klein, S.L.; Kriegsfeld, L.J.; Dawson, V.L.; Dawson, T.M.; Snyder, S.H. Nitric oxide-dependent penile erection in mice lacking neuronal nitric oxide synthase. Mol. Med. 1996, 2, 288-296. [CrossRef]

39. Huang, P.L.; Huang, Z.; Mashimo, H.; Bloch, K.D.; Moskowitz, M.A.; Bevan, J.A.; Fishman, M.C. Hypertension in mice lacking the gene for endothelial nitric oxide synthase. Nature 1995, 377, 239-242. [CrossRef] 
40. Huang, A.; Sun, D.; Shesely, E.G.; Levee, E.M.; Koller, A.; Kaley, G. Neuronal NOS-dependent dilation to flow in coronary arteries of male eNOS-KO mice. Am. J. Physiol. 2002, 282, H429-H436. [CrossRef]

41. Goodwin, B.L.; Solomonson, L.P.; Eichler, D.C. Argininosuccinate synthase expression is required to maintain nitric oxide production and cell viability in aortic endothelial cells. J. Biol Chem. 2004, 279, 18353-18360. [CrossRef]

42. Elms, S.; Chen, F.; Wang, Y.; Qian, J.; Askari, B.; Yu, Y.; Pandey, D.; Iddings, J.; Caldwell, R.; Fulton, D.J.R. Insights into the arginine paradox: Evidence against the importance of subcellular location of arginase and eNOS. Am. J. Physiol. Circ. Physiol. 2013, 305, H651-H666. [CrossRef]

43. Wijnands, K.A.; Hoeksema, M.A.; Meesters, D.M.; van den Akker, N.M.; Molin, D.G.; Briede, J.J.; Ghosh, M.; Kohler, S.E.; van Zandvoort, M.A.; de Winther, M.P.; et al. Arginase-1 deficiency regulates arginine concentrations and NOS2-mediated NO production during endotoxemia. PLoS ONE 2014, 9, e86135. [CrossRef]

44. Van Wijck, K.; Wijnands, K.A.; Meesters, D.M.; Boonen, B.; van Loon, L.J.; Buurman, W.A.; Dejong, C.H.; Lenaerts, K.; Poeze, M. L-citrulline Improves Splanchnic Perfusion and Reduces Gut Injury during Exercise. Med. Sci. Sports Exerc. 2014. [CrossRef]

45. Laubach, V.E.; Shesely, E.G.; Smithies, O.; Sherman, P.A. Mice lacking inducible nitric oxide synthase are not resistant to lipopolysaccharide-induced death. Proc. Natl. Acad. Sci. USA 1995, 92, 10688-10692. [CrossRef]

46. Groner, W.; Winkelman, J.W.; Harris, A.G.; Ince, C.; Bouma, G.J.; Messmer, K.; Nadeau, R.G. Orthogonal polarization spectral imaging: A new method for study of the microcirculation. Nat. Med. 1999, 5, 1209-1212. [CrossRef]

47. Spronk, P.E.; Ince, C.; Gardien, M.J.; Mathura, K.R.; Oudemans-van Straaten, H.M.; Zandstra, D.F. Nitroglycerin in septic shock after intravascular volume resuscitation. Lancet 2002, 360, 1395-1396. [CrossRef]

48. De Backer, D.; Hollenberg, S.; Boerma, C.; Goedhart, P.; Buchele, G.; Ospina-Tascon, G.; Dobbe, I.; Ince, C. How to evaluate the microcirculation: Report of a round table conference. Crit. Care 2007, 11, R101. [CrossRef]

49. Verdant, C.L.; De Backer, D.; Bruhn, A.; Clausi, C.M.; Su, F.; Wang, Z.; Rodriguez, H.; Pries, A.R.; Vincent, J.L. Evaluation of sublingual and gut mucosal microcirculation in sepsis: A quantitative analysis. Crit. Care Med. 2009, 37, 2875-2881. [CrossRef] 